\title{
Serum paraoxonase 1 activity in patients with iron deficiency anemia
}

Yildiz Okuturlar ${ }^{1}$, Asuman Gedikbasi², Nilgul Akalin ${ }^{3}$, Meral Gunaldi ${ }^{4}$, Deniz Yilmaz ${ }^{1}$, Meral Mert $^{5}$, Ozlem Harmankaya ${ }^{1}$, Aliye Soylu ${ }^{6}$, Pinar Karakaya ${ }^{5}$, Abdulbaki Kumbasar $^{1}$

\author{
${ }^{1}$ Department of Internal Medicine, Bakırkoy Dr. Sadi Konuk Training and Research \\ Hospital, Istanbul, Turkey \\ ${ }^{2}$ Department of Biochemistry, Bakirkoy Dr. Sadi Konuk Training and Research \\ Hospital, Istanbul, Turkey \\ ${ }^{3}$ Department of Nephrology, Bakirkoy Dr. Sadi Konuk Training and Research Hospital, \\ Istanbul, Turkey \\ ${ }^{4}$ Department of Oncology, Bakirkoy Dr. Sadi Konuk Training and Research Hospital, \\ Istanbul, Turkey \\ ${ }^{5}$ Department of Endocrinology and Metabolism, Bakırkoy Dr. Sadi Konuk Training \\ and Research Hospital, Istanbul, Turkey \\ ${ }^{6}$ Department of Gastroenterology, Bakırkoy Dr. Sadi Konuk Training and Research \\ Hospital, Istanbul, Turkey
}

Submitted: 28 August 2014

Accepted: 19 October 2014

Arch Med Sci 2016; 12, 4: 697-703

DOI: 10.5114 /aoms.2015.48730

Copyright (C) 2016 Termedia \& Banach

\section{Abstract}

Introduction: In this study we aimed to detect paraoxonase 1 (PON-1) activity in iron deficiency anemia (IDA) and to compare it with healthy controls by observing the change after iron therapy.

Material and methods: In this study, 50 adult patients with IDA and 40 healthy subjects were enrolled. All patients were analyzed at the beginning and after treatment according to laboratory assessments.

Results: Mean paraoxonase and arylesterase activities in the iron deficiency anemia group were significantly lower than mean activities of the control group $(102.4 \pm 19.2 \mathrm{U} / /$ and $163.3 \pm 13.68 \mathrm{U} / \mathrm{l}$, respectively and $157.3 \pm 26.4 \mathrm{U} / \mathrm{l}$ and $256.1 \pm 24.6 \mathrm{U} / \mathrm{l}$, respectively; $p=0.0001$ for both). Paraoxonase and arylesterase activities significantly increased after treatment for IDA (143.2 \pm 13.9 and $197.6 \pm 27.9 \mathrm{U} / \mathrm{l}$, respectively, $p=0.0001$ ). Mean activities after treatment with iron were significantly lower than mean activities in the control group ( $p=0.002 ; p=0.0001$ respectively).

Conclusions: Paraoxonase and arylesterase activities in patients with IDA significantly increased after treatment with iron therapy. In adults IDA may also be one of the factors associated with increased risk of atherosclerosis.

Key words: paraoxonase, arylesterase, iron deficiency anemia, atherosclerosis.

\section{Introduction}

Anemia is mostly caused by iron deficiency, which is the most common nutritional deficiency. Insufficient iron intake, impaired absorption and physiologic or pathologic blood loss cause iron deficiency anemia (IDA) [1]. The World Health Organization (WHO) defines anemia as a decrease in hemoglobin $(\mathrm{Hb})$ concentration below $12 \mathrm{~g} / \mathrm{dl}$ for women and $13 \mathrm{~g} / \mathrm{dl}$ for men [2].

\author{
Corresponding author: \\ Yildiz Okuturlar \\ Department \\ of Internal Medicine \\ Bakırkoy Dr. Sadi Konuk \\ Training and Research \\ Hospital \\ Atakent mahallesi. \\ 1203. Sok. \\ Kapi 26 B Daire: 15 \\ Kucukcekmece \\ Istanbul, Turkey \\ Phone: +90 5321200893 \\ Fax: +90 2125424491 \\ E-mail: y.okuturlar@gmail. \\ com
}


Iron deficiency anemia is more common in women due to the iron loss through menstrual bleeding. Recently the focus on the relationship between iron metabolism and the development of atherosclerosis has increased significantly. Various studies have shown that anemia is an independent cardiovascular risk factor and an indicator of poor prognosis in patients with coronary artery disease (CAD) [3]. Studies of IDA patients also showed lower activity of antioxidant enzymes as a result of the influence of iron levels on oxidative stress. Paraoxonase 1 (PON1) enzyme, which is an antioxidant and is synthesized by the liver, is transported in plasma bound to high-density lipoprotein (HDL). Three known activities of this enzyme are paraoxonase (PON), arylesterase (ARE) and diazoxonase. It provides the antiatherogenic properties of $\mathrm{HDL}$, by preventing low-density lipoprotein (LDL) oxidation $[4,5]$. Paraoxonase 1 deficiency is very sensitive to development of atherosclerosis and cardiovascular disease [6]. It was found in some studies that oxidative stress increased in patients with anemia due to a decrease in PON1 activity. In our study we aimed to determine PON1 activity and whether iron therapy has an effect on PON1 activity.

\section{Material and methods}

This prospective clinical trial was carried out from February 2012 to December 2013. A total of 56 patients with IDA were enrolled in the study. After examination of IDA etiology, 6 patients were excluded from the study because of colonic carcinoma, renal cell carcinoma, infection availability, cirrhosis, adrenal non-functional adenoma, and Cushing's syndrome. The remaining 50 IDA patients (mean age: $45.4 \pm 16.3$ years, 43 females) were compared with 40 (mean age: $49.95 \pm 10.2$ years, 29 females) age- and gender-matched healthy controls. The average follow-up period was $129 \pm 131.5$ (24-451 days). Informed consent was obtained from all participants, and the protocol was approved by the Ethics Committee of the hospital.

Inclusion criteria were as follows: hemoglobin concentration $<10 \mathrm{~g} / \mathrm{dl}$, hematocrit $(\mathrm{Hct})<31 \%$, mean corpuscular volume (MCV) $<76 \mathrm{fl}$, red blood cell distribution width (RDW) $>15 \%$, transferrin saturation (Tfs) $<15 \%$ and ferritin $<20 \mu \mathrm{g} / \mathrm{l}$. Exclusion criteria included diabetes mellitus (DM) or other endocrine disorders, hypertension, hepatic or renal pathologies, chronic inflammatory diseases such as rheumatoid arthritis, excessive tobacco use (> 10 cigarettes/day) or ethanol (> $30 \mathrm{~g} /$ day) consumption, cardiovascular disease treatment with antioxidants or drugs that could affect lipid or carbohydrate metabolism, generalized malig- nancies or local infection, and anemia of other causes.

Complete cell count, biochemical investigations, and gynecological examination were performed for patients with IDA, and gastrointestinal endoscopy was performed for patients who were older than 40 years and had no hypermenorrhea.

\section{Treatment protocol}

The oral ferrous sulfate $\left(\mathrm{Fe}^{++}\right)$treatment was started in the patients. A ferrous sulfate tablet taken orally three times daily between meals provides an oral dose of $195 \mathrm{mg}$ of elemental iron per day. Those who cannot tolerate oral iron therapy were treated with iron sucrose (IVIS) $(200 \mathrm{mg} /$ day for two consecutive days) intravenously after calculation of iron deficiency. The dose for IVIS was calculated according to an adapted Ganzoni formula: dose $[\mathrm{mg}]=($ body weight $[\mathrm{kg}] \times($ target $\mathrm{Hb}[\mathrm{g} / \mathrm{dl}]-$ actual $\mathrm{Hb}[\mathrm{g} / \mathrm{dl}]) \times 2.4+500 \mathrm{mg}$ (for iron stores)) [7]. Iron sucrose was given as $100 \mathrm{mg}$ (2 ampoules, each of $2.5 \mathrm{ml}$ ) in $100 \mathrm{ml}$ of $0.9 \%$ normal saline infusion over $1 \mathrm{~h}$ every 3 days up to the total calculated dose. A complete blood count and serum ferritin levels were measured once a month. During that time no antioxidant diet or exercise program which might have an effect on oxidative status was provided. Treatment was continued until ferritin $>20 \mu \mathrm{g} / \mathrm{l}, \mathrm{Hb}=12 \mathrm{~g} / \mathrm{dl}$ for females, $13 \mathrm{~g} / \mathrm{dl}$ for males.

\section{Blood sample collection}

After a 12-h overnight fast, venous blood was drawn from the antecubital vein two times before and after iron treatment. The recovery hemoglobin levels of iron treatment were $12 \mathrm{~g} / \mathrm{dl}$ and $13 \mathrm{~g} / \mathrm{dl}$, for women and men respectively. The tubes were centrifuged at $4000 \mathrm{rpm}$ (10 $\mathrm{min}$ ) to remove the plasma and serum. The plasma and serum samples were kept at $-80^{\circ} \mathrm{C}$ until analysis of PON 1 activity.

\section{Measurement of paraoxonase and arylesterase activities}

PON and ARE activities were determined using a novel automated measurement method developed by Erel (Relassay, Turkey) [8]. Briefly, the rate of paraoxon hydrolysis was measured by the increased absorbance at $412 \mathrm{~nm}$ at $25^{\circ} \mathrm{C}$. The PON activity is expressed as $\mathrm{U} / \mathrm{l}$ serum. The coefficient of variation (CV) for individual samples was $1.8 \%$. ARE activity was measured spectrophotometrically using phenyl acetate. The reaction was started by the addition of the serum; the increase in absorbance was read at $270 \mathrm{~nm}$. Enzymatic activity was calculated from the molar absorptivity coefficient of the produced phenol. One unit of ARE ac- 
tivity was defined as 1 umol of phenol generated/ min under the defined assay conditions and expressed as U/I serum. The CV for individual serum samples was $3.3 \%$.

\section{Other variables}

Serum glucose, urea, creatinine, LDL cholesterol, HDL cholesterol, triglyceride, iron and total iron binding capacity (TIBC), ferritin, TSH, fT3, fT4 and other biochemical parameters were determined by the Abbott Architect C16200 Integrated System and using commercial kits (Abbott Laboratories, IL, USA). Complete blood count was determined in a Coulter LH 750 hematology analyzer (Beckman Coulter, CA, USA).

\section{Statistical analysis}

Statistical calculations were performed with Number Cruncher Statistical System 2007 Statistical Software (Utah, USA) for Windows. Besides standard descriptive statistical calculations (mean and standard deviation), the unpaired $t$ test was used in the comparison of groups, the paired $t$-test was employed in the assessment of preand post-treatment values, and the $\chi^{2}$ test was performed during the evaluation of qualitative data. Pearson's correlation test was used to determine relationships between research variables. Linear regressions analysis was performed to determine the independent effect of factors associated with PON. A $p$-value of $<0.05$ was considered significant.

\section{Results}

Demographic and biochemical parameters of IDA patients and control subjects are shown in Table I. There was no significant difference in gender, age, $\mathrm{BMI}$ or biochemical parameters $(p>0.05) \mathrm{Hb}$ $(p=0.001)$, Hct $(p=0.001), \operatorname{MCV}(p=0.001)$, ferritin $(p=0.001)$, total cholesterol $(p=0.001)$, and LDL cholesterol ( $p=0.001)$ levels were significantly lower in IDA patients. IDA patients had lower total cholesterol and LDL cholesterol concentrations than the control group (Table I). Before treatment, the hemoglobin level was $7.46 \pm 1.23$ and the ferritin level was $2.76 \pm 2.02$, and after treatment they were $12.05 \pm 0.87$ and $28.41 \pm 16$, respectively ( $p=0.0001$ for both).

Mean PON and ARE activities in the iron deficiency anemia group (102.44 $\pm 19.29 \mathrm{U} / \mathrm{l}$ and $163.33 \pm 13.68 \mathrm{U} /$, respectively) were significantly lower than mean activity of the control group $(157.37 \pm 26.43 \mathrm{U} / \mathrm{l}$ and $256.11 \pm 24.62 \mathrm{U} / \mathrm{l}$, respectively; $p=0.0001$ for both). Mean activity after treatment (143.28 \pm 13.98 and $197.61 \pm 27.95 \mathrm{U} /$, respectively) was significantly lower than mean activity of the control group $(p=0.002, p<0.001$, respectively). PON and ARE activities significantly increased after treatment with iron in iron deficiency anemia ( $p=0.0001$ for both) (Table II).

Positive correlations were found between paraoxonase, ARE activity and $\mathrm{Hb}(r=879, p=0.0001$; $r=0.889, p=0.0001$, respectively). No significant correlation was observed with ferritin. Correlation analyses between PON, ARE and other parameters are shown in Table III.

Linear regression analysis was performed between $\mathrm{Hb}, \mathrm{MCV}$, iron, TIBC, platelet value and PON values, and a statistically significant relationship was observed with a $R^{2}$ value of 0.731 and corrected $R^{2}$ value of $0.715(p=0.0001)$. At the end of the linear regression $\mathrm{PON}$ was associated with $\mathrm{Hb}$ and MCV $(p=0.0001)$ (Table IV).

Linear regression analysis was performed between $\mathrm{Hb}, \mathrm{MCV}$, iron, TIBC, platelets and ARE values, and a statistically significant relationship was observed with a $R^{2}$ value of 0.764 and corrected $R^{2}$ value of $0.749(p=0.0001)$. At the end of the linear regression ARE was associated with $\mathrm{Hb}$ and MCV $(p=0.0001)$ (Table V).

\section{Discussion}

In this study we investigated PON and ARE activities in patients with IDA before and after iron treatment. The results showed a decrease in PON and ARE in IDA, but these activities significantly increased after treatment with iron.

Aslan et al. observed in their study that in adults with IDA, PON and ARE enzyme activities are reduced. On the other hand, Koç et al. did not observe such a reduction in children $[9,10]$. This may be due to the decrease of enzyme activity with age [11]. Our results are consistent with those of Aslan et al. Another study showed a significant positive correlation between serum PON1 activity and $\mathrm{Hb}$ concentration in patients with $\beta$-thalassemia-trait subjects, as in our study. The authors suggested that PON1 activity may indicate a decreased antioxidant effect on LDL cholesterol with increasing anemia and increased atherosclerosis in those patients [12].

Approximately $50 \%$ of the etiology may be explained by major risk factors of atherosclerosis [13]. Therefore, new risk factors of atherosclerosis must be investigated. The HDL cholesterol parameter is inversely correlated with the risk of cardiovascular disease. The antioxidant property of HDL cholesterol refers to PON1 activity. Recently, it was suggested that important determinants of the presence of CAD are low PON1 activity and concentration [14]. Different studies have shown that decreased PON and ARE activities are risk factors for not only cardiovascular disorders but also non-cardiac diseases [15-19]. PON1 levels have been associated with pharmacological, 
Table I. Demographic and clinical parameters in patients with IDA and controls

\begin{tabular}{|c|c|c|c|}
\hline Parameter & $\operatorname{IDA}(n=50)$ & Controls $(n=40)$ & $P$-value \\
\hline Age [years] & $45.4 \pm 16.36$ & $49.95 \pm 10.28$ & 0.129 \\
\hline BMI $\left[\mathrm{kg} / \mathrm{m}^{2}\right]$ & $27.50 \pm 4.43$ & $27.76 \pm 5.73$ & 0.815 \\
\hline $\mathrm{Hb}[\mathrm{g} / \mathrm{dl}]$ & $7.35 \pm 1.33$ & $13.07 \pm 2.55$ & 0.0001 \\
\hline Hct (\%) & $24.63 \pm 3.41$ & $40.77 \pm 4.38$ & 0.0001 \\
\hline $\operatorname{MCV}[\mathrm{fl}]$ & $62.41 \pm 5.8$ & $88.78 \pm 7.31$ & 0.0001 \\
\hline Thrombocytes $\left[/ \mathrm{mm}^{3} \times 10^{3}\right]$ & $353.64 \pm 102.2$ & $265.15 \pm 61.42$ & 0.0001 \\
\hline Iron $[\mu \mathrm{g} / \mathrm{dl}]$ & $16.9 \pm 20.03$ & $77.53 \pm 30.26$ & 0.0001 \\
\hline $\mathrm{IBC}[\mu \mathrm{g} / \mathrm{dl}]$ & $417.76 \pm 78.2$ & $265.95 \pm 59.21$ & 0.0001 \\
\hline Ferritin [ng/ml] & $3.11 \pm 2.48$ & $34.1 \pm 26.58$ & 0.0001 \\
\hline $\mathrm{TC}[\mathrm{mg} / \mathrm{dl}]$ & $161.86 \pm 39.65$ & $189.28 \pm 29.94$ & 0.0001 \\
\hline $\mathrm{TG}[\mathrm{mg} / \mathrm{dl}]$ & $111.12 \pm 94.31$ & $116.1 \pm 65.42$ & 0.777 \\
\hline LDL-C [mg/dl] & $92.88 \pm 31.49$ & $117.23 \pm 23.42$ & 0.0001 \\
\hline $\mathrm{HDL}-\mathrm{C}[\mathrm{mg} / \mathrm{dl}]$ & $48.66 \pm 13.32$ & $49.3 \pm 11.54$ & 0.811 \\
\hline
\end{tabular}

$B M I$ - body mass index, $\mathrm{Hb}$ - hemoglobin, Hct - hematocrit, MCV - mean corpuscular volume, IBC - iron binding capacity, TG - triglyceride, $T C$ - total cholesterol, HDL-C - high-density lipoprotein cholesterol, LDL-C - low-density lipoprotein cholesterol, IDA - iron deficiency anemia. Values are mean $\pm S D$

Table II. Mean values of paraoxonase and arylesterase activities in the iron deficiency anemia groups before and after treatment and in the control group

\begin{tabular}{|c|c|c|c|}
\hline Parameter & IDA $(n=40)$ & Controls $(n=40)$ & $P$-value \\
\hline PON [U/I] (before treatment) & $102.44 \pm 19.29$ & $157.37 \pm 26.43$ & 0.0001 \\
\hline PON [U/I] (after treatment) & $143.28 \pm 13.98$ & & 0.002 \\
\hline$P$-value & 0.0001 & & \\
\hline ARE [U/I] (before treatment) & $163.33 \pm 13.68$ & $256.11 \pm 24.62$ & 0.0001 \\
\hline ARE $[U / I]$ (after treatment) & $197.61 \pm 27.95$ & & 0.0001 \\
\hline$P$-value & 0.0001 & & \\
\hline
\end{tabular}

$P O N$ - paraoxonase activity, ARE - arylesterase. Values are mean $\pm S D$.

Table III. Correlation analyses between PON, ARE and other parameters

\begin{tabular}{|lcccccccccc|}
\hline Parameter & ARE & Hb & Hct & MCV & Iron & IBC & Ferritin & LDL & HDL \\
\hline PON & $R$-value & 0.812 & 0.815 & 0.849 & 0.799 & 0.62 & -0.555 & 0.153 & 0.508 & 0.086 \\
\cline { 2 - 11 } & P-value & 0.0001 & 0.0001 & 0.0001 & 0.0001 & 0.0001 & 0.0001 & 0.149 & 0.0001 & 0.419 \\
\hline ARE & $R$-value & & 0.815 & 0.884 & 0.846 & 0.716 & -0.651 & 0.046 & 0.442 & 0.066 \\
\cline { 2 - 11 } & P-value & & 0.0001 & 0.0001 & 0.0001 & 0.0001 & 0.0001 & 0.669 & 0.0001 & 0.537 \\
\hline
\end{tabular}

$P O N$ - paraoxonase, ARE - arylesterase, $\mathrm{Hb}$ - hemoglobin, $\mathrm{Hct}$ - hematocrit, $\mathrm{MCV}$ - mean corpuscular volume, IBC-iron binding capacity, $L D L-C$ - low-density lipoprotein cholesterol, HDL-C - high-density lipoprotein cholesterol.

nutritional, genetic and infectious processes [20]. Although an initiating factor in atherosclerosis may be oxidative stress, it is not clearly the only underlying mechanism [21, 22]. PON1 is a protective enzyme for LDL cholesterol oxidation, and it is an important molecule in the pathogenesis of atherosclerosis [23]. In several studies increased oxidative stress has been attributed to the low PON1 activity in metabolic syndrome and obesity [24-26]. Additionally, PON1 activity was lower in patients with CAD, type 2 diabetes mellitus and hypercholesterolemia [27, 28]. It was found in this study that PON1 activity in IDA was low. So the low PON1 activity may create an increased tendency for the development of CAD in IDA. 
Table IV. Linear regression analysis for paraoxonase

A

\begin{tabular}{|ccccc|}
\hline$R$ & $R^{2}$ & Adjusted $R^{2}$ & SE of the estimate & $P$-value \\
\hline 0.855 & 0.731 & 0.715 & 19.17 & 0.0001 \\
\hline
\end{tabular}

Predictors: (constant), PIt, MCV, IBC, iron, $\mathrm{Hb}$.

B

\begin{tabular}{|c|c|c|c|c|c|}
\hline \multirow[t]{2}{*}{ Parameter } & \multicolumn{2}{|c|}{ Unstandardized coefficients } & \multicolumn{2}{|c|}{ Standardized coefficients } & \multirow[t]{2}{*}{$P$-value } \\
\hline & $B$ & SE & $\beta$ & $t$ & \\
\hline (Constant) & -33.33 & 26.87 & & -1.24 & 0.218 \\
\hline $\mathrm{Hb}$ & 5.21 & 1.05 & 0.50 & 4.95 & 0.0001 \\
\hline MCV & 1.18 & 0.30 & 0.48 & 3.92 & 0.0001 \\
\hline Iron & 0.03 & 0.09 & 0.03 & 0.31 & 0.761 \\
\hline IBC & 0.04 & 0.03 & 0.12 & 1.28 & 0.205 \\
\hline Plt & 0.02 & 0.02 & 0.05 & 0.84 & 0.406 \\
\hline
\end{tabular}

Dependent variable: paraoxonase. $\mathrm{Hb}$ - hemoglobin, MCV - mean corpuscular volume, IBC - iron binding capacity, Plt - platelets.

Table V. Linear regression analysis for arylesterase

A

\begin{tabular}{|ccccc|}
\hline$R$ & $R^{2}$ & Adjusted $R^{2}$ & SE of the estimate & $P$-value \\
\hline 0.874 & 0.764 & 0.749 & 25.01 & 0.0001 \\
\hline
\end{tabular}

Predictors: (constant), Plt, IBC, $\mathrm{Hb}$, iron, MCV.

B

\begin{tabular}{|lccccc|}
\hline & \multicolumn{1}{c}{ Unstandardized coefficients } & \multicolumn{2}{c|}{ Standardized coefficients } & \multicolumn{1}{c}{$\boldsymbol{P}$-value } \\
\cline { 2 - 5 } & $\boldsymbol{B}$ & $\mathrm{SE}$ & $\beta$ & 1.07 & 0.289 \\
\hline (Constant) & 37.40 & 35.05 & & 3.75 & 0.0001 \\
\hline $\mathrm{Hb}$ & 5.15 & 1.37 & 0.36 & 3.89 & 0.0001 \\
\hline MCV & 1.52 & 0.39 & 0.44 & 1.42 & 0.159 \\
\hline Iron & 0.17 & 0.12 & 0.13 & 0.14 & 0.886 \\
\hline IBC & 0.01 & 0.04 & 0.01 & -0.65 & 0.519
\end{tabular}

Dependent variable: arylesterase. $\mathrm{Hb}$ - hemoglobin, MCV - mean corpuscular volume, IBC - iron binding capacity, Plt - platelets.

Some studies have indicated serum PON-1 activity to be related to various lipid and lipoprotein parameters such as HDL and triglycerides [29, 30]. We did not observe such a correlation with HDL and triglycerides. In our study, serum PON1 activity was low in IDA patients with normal lipid parameters. A decrease in HDL levels in patients could result in a decrease in serum PON1 [31]. In our study, despite the fact that HDL was not different in the control group, PON1 activity was lower. Therefore, in this group of patients, PON1 activity might be affected not only by differences in HDL levels, but also by other factors such as lipid peroxidation products [32]. The serum PON1 activity is highly variable and its regulation is complex. Decreased
PON may lead to a reduction in antioxidant capacity of HDL and contribute to accelerated development of CAD. In our study, even if LDL and cholesterol levels were significantly lower than in controls and there was no significant difference in HDL level, reduced PON1 activity could also be a result of increased oxidative stress. However, in accordance with a previous report, we found no correlation between PON activity and HDL cholesterol [33].

There is limited evidence showing that increased iron stores and high-dose intravenous (IV) iron therapy may create oxidative stress (OS) in haemodialysis (HD) patients [34, 35]. However, the minimum level of serum ferritin to induce oxidative tissue damage is unknown [36]. The re- 
lationship between ferritin and oxidative stress and PON-1 is unclear. In our study, while PON-1 levels were correlated with iron and iron binding capacity, there was no relationship with ferritin level. This might be because of the follow-up time, duration of iron therapy and number of patients.

Current guidelines suggest the treatment of the underlying cause of iron deficiency, but all patients should have iron supplementation both to correct anemia and replenish body stores. Oral iron is suggested to be continued for 3 months after the iron deficiency has been corrected so that stores are replenished [37]. In our study the $\mathrm{Hb}$ levels increased to normal levels after therapy and ferritin levels reached the levels of the control group. The mean treatment duration of our patients was 4 months (129 \pm 131.5 days). In current guidelines it is suggested to continue the iron supplementation for 3 months to replenish the stores, but the target ferritin level is not clear. In our study the ferritin level of the patients was the same as that of the control group after treatment. After treatment, $\mathrm{Hb}$ and ferritin levels of patients reached the same levels of the control group, but the increase in PON1 activity of patients did not reach the levels of the control group. There is no clear result about the duration of iron treatment which will bring PON and ARE levels to normal regardless of the levels of $\mathrm{Hb}$ and ferritin.

The small sample size was a limitation in our study because patients with IDA did not come back after therapy for follow-up.

In conclusion, in this study, we observed that PON-1 activity was significantly lower in patients having iron deficiency anemia than in controls, and iron therapy increased the activity of these enzymes. However, both positive and linear correlations between PON1 activity and hematological and iron status parameters proved that this enzyme is sensitive to the degree of iron deficiency.

At the time of diagnosis, close follow-up of the patients with IDA is necessary for the inhibition of cardiovascular risk, even if they have normal serum lipid levels. Our results may indicate that iron deficiency anemia in adults may also be one of the factors associated with increased risk of atherosclerosis in later life due to decreased PON-1 activity.

\section{Acknowledgments}

We thank Rana Konyalioglu for statistical analysis, Bulent Altundal, who provided medical writing support, and Gülsüm Can, who is the nurse of our clinic.

\section{Conflict of interest}

The authors declare no conflict of interest.

\section{References}

1. Clark SF. Iron deficiency anemia. Nutr Clin Pract 2008; 23: $128-41$

2. World Health Organization. "Worldwide prevalence of anaemia 1993-2005: WHO global database on anaemia." (2008).http://apps.who.int/iris/bitstream/10665/43894/ 1/9789241596657_eng.pdf. Accessed 01.08.2014.

3. Chonchol M, Christopher N. Hemoglobin levels and coronary artery disease. Am Heart J 2008; 155: 494-8.

4. Teiber JF, Kramer GL, Haley RW. Methods for measuring serum activity levels of the $192 \mathrm{Q}$ and R isoenzymes of paraoxonase 1 in QR heterozygous individuals. Clin Chem 2013; 59: 1251-9.

5. Yildirim K, Uzkeser H, Keles M, et al. Cu/Zn-superoxide dismutase, paraoxonase and arylesterase activities and malondialdehyde levels in patients with familial mediterranean fever. Bratisl Med J 2012; 113: 561-4.

6. Litvinov D, Mahini H, Garelnabi M. Antioxidant and anti-inflammatory role of paraoxonase 1 : implication in arteriosclerosis diseases. N Am J Med Sci 2012; 4: 523-32.

7. Reinisch W, Staun M, Tandon RK, et al. A randomized, open-label, non-inferiority study of intravenous iron isomaltoside 1,000 (Monofer) compared with oral iron for treatment of anemia in IBD (PROCEED). Am J Gastroenterol 2013; 108: 1877-88.

8. Ozturk E, Balat O, Dikensoy E, et al. No association between serum paraoxonase, arylesterase activities, and hydatidiform mole. Int J Gynecol Cancer 2011; 21: 149-52.

9. Aslan M, Kosecik M, Horoz M, Selek S, Celik H, Erel O. Assessment of paraoxonase and arylesterase activities in patients with iron deficiency anemia. Atherosclerosis 2007; 191: 397-402.

10. Koç A, Cengiz M, Ozdemir ZC, Celik H. Paraoxonase and arylesterase activities in children with iron deficiency anemia and vitamin B12 deficiency anemia. Pediatr Hematol Oncol 2012; 29: 345-53.

11. Kumar D, Rizvi SI. Age-dependent paraoxonase 1 (PON1) activity and LDL oxidation in Wistar rats during their entire lifespan. Sci World J 2014; 2014: 538049.

12. Labib HA, Etewa RL, Gaber OA, Atfy M, Mostafa TM, Barsoum I. Paraoxonase- 1 and oxidative status in common Mediterranean beta-thalassaemia mutations trait, and their relations to atherosclerosis. J Clin Pathol 2011; 64: 437-42.

13. Mackness M, Durrington P, Mackness B. Paraoxonase 1 activity, concentration and genotype in cardiovascular disease. Curr Opin Lipidol 2004; 15: 399-404.

14. Zhou C, Cao J, Shang L, et al. Reduced paraoxonase 1 activity as a marker for severe coronary artery disease. Dis Markers 2013; 35: 97-103.

15. Takci Z, Bilgili SG, Karadag AS, Kucukoglu ME, Selek S, Aslan M. Decreased serum paraoxonase and arylesterase activities in patients with rosacea. J Eur Acad Dermatol Venereol 2015; 29: 367-70.

16. Szántó A, Harangi M, Seres I, Paragh G, Zeher M. Decreased human paraoxonase- 1 activity in patients with Sjögren's syndrome. Int Immunol 2010; 22: 605-9.

17. Acay A, Erdenen F, Altunoglu E, et al. Evaluation of serum paraoxonase and arylesterase activities in subjects with asthma and chronic obstructive lung disease. Clin Lab 2013; 59: 1331-7.

18. Li Y, Zhai R, Li H, Mei X, Qiu G. Prognostic value of serum paraoxonase and arylesterase activity in patients with sepsis. J Int Med Res 2013; 41: 681-7. 
19. Atay AE, Sakar MN, Culcu N, et al. The evaluation of paraoxonase 1 activity in patients with gestational diabetes. Acta Medica Mediterr 2013; 29: 653-7.

20. Gupta N, Gill K, Singh S. Paraoxonases: structure, gene polymorphism and role in coronary artery disease. Indian J Med Res 2009; 130: 361-8.

21. Ren H, Zhou X, Luan Z, et al. The relationship between carotid atherosclerosis, inflammatory cytokines, and oxidative stress in middle-aged and elderly hemodialysis patients. Int J Nephrol 2013; 2013: 835465.

22. Zampetaki A, Dudek K, Mayr M. Oxidative stress in atherosclerosis: the role of microRNAs in arterial remodeling. Free Rad Biol Med 2013; 64: 69-77.

23. She ZG, Chen HZ, Yan Y, Li H, Liu DP. The human paraoxonase gene cluster as a target in the treatment of atherosclerosis. Antioxid Redox Signal 2012; 16: 597-632.

24. Zaki ME, El-Bassyouni H, Kamal S, El-Gammal M, Youness $E$. Association of serum paraoxonase enzyme activity and oxidative stress markers with dyslipidemia in obese adolescents. Indian J Endocrinol Metab 2014; 18: 340-4.

25. Aslan M, Horoz M, Sabuncu T, Celik H, Selek S. Serum paraoxonase enzyme activity and oxidative stress in obese subjects. Pol Arch Med Wewn 2011; 121: 181-6.

26. Tabur S, Torun AN, Sabuncu T, et al. Non-diabetic metabolic syndrome and obesity do not affect serum paraoxonase and arylesterase activities but do affect oxidative stress and inflammation. Eur J Endocrinol 2010; 162: 535-41.

27. Kostapanos MS, Elisaf MS. High density lipoproteins and type 2 diabetes: emerging concepts in their relationship. World J Exp Med 2014; 4: 1-6.

28. Zhu Y, Huang X, Zhang Y, et al. Anthocyanin supplementation improves HDL-associated paraoxonase 1 activity and enhances cholesterol efflux capacity in subjects with hypercholesterolemia. J Clin Endocrinol Metab 2014; 99: 561-9.

29. Jiang XL, Li M, Zhou JG, et al. Plasma paraoxonase-1, oxidized low-density lipoprotein and lipid peroxidation levels in gout patients. Cell Biochem Biophys 2011; 61: 461-6.

30. Rosenblat M, Ward S, Volkova N, Hayek T, Aviram M. VLDL triglycerides inhibit HDL-associated paraoxonase 1 (PON1) activity: in vitro and in vivo studies. BioFactors 2012; 38: 292-9.

31. González Al, Brites F, Elbert A, et al. Relation between paraoxonase activity, other HDL components and inflammatory state in hemodialyzed patients. Medicina (B Aires) 2010; 70: 508-12.

32. Schiavon R, Battaglia P, De Fanti E, et al. HDL3-related decreased serum paraoxonase (PON) activity in uremic patients: comparison with the PON1 allele polymorphism. Clin Chim Acta 2002; 324: 39-44.

33. Mackness B, Durrington P, McElduff P, et al. Low paraoxonase activity predicts coronary events in the Caerphilly Prospective Study. Circulation 2003; 107: 2775-9.

34. Swarnalatha G, Ram R, Neela P, Naidu MUR, Dakshina Murty KV. Oxidative stress in hemodialysis patients receiving intravenous iron therapy and the role of $\mathrm{N}$-acetylcysteine in preventing oxidative stress. Saudi J Kidney Dis Transpl 2010; 21: 852-8.

35. Kumbasar A, Gursu M, Kaya C, et al. The effect of different doses and types of intravenous iron on oxidative stress and inflammation in hemodialysis patients. J Nephrol 2012; 25: 825-32.

36. Fishbane S, Kalantar-Zadeh K, Nissenson AR. Serum ferritin in chronic kidney disease: reconsidering the upper limit for iron treatment. Semin Dialysis 2004; 17: 336-41.
37. Goddard AF, James MW, McIntyre AS, Scott BB. Guidelines for the management of iron deficiency anaemia. Gut 2011; 60: 1309-16. 